\title{
Fast-Slow Scale Bifurcation in Higher Order Open Loop Current-Mode Controlled DC-DC Converters
}

\author{
I. Daho*, D. Giaouris*, S. Banerjee**, B. Zahawi*, and V. Pickert* \\ * School of Electrical, Electronic and Computer Engineering, Newcastle University, Newcastle upon Tyne,UK. \\ ibrahim.daho@ncl.ac.uk. \\ ** Department of Electrical Engineering, Indian Institute of Technology, Kharagpur, India. soumitro@ee.iitkgp.ernet.in
}

\begin{abstract}
Higher order converters, without an external voltage control loop, have been known not to exhibit a fast-slow scale bifurcation interaction, as the slow-scale bifurcation has generally been believed to be caused by parameter changes in the outer loop. In this paper, it is shown that a current-mode controlled Ćuk converter can exhibit an interaction between fast-scale and slow-scale bifurcations even in the absence of this closed outer voltage control loop. The phenomenon is probed using an approach based on the system's monodromy matrix that does not only predict this instability but also provides a systematic method for the development of new control strategies to avoid the onset of this bifurcation. Analytical and numerical results prove that the new controller greatly extends the stable region of operation of the converter.
\end{abstract}

Keywords: Ćuk converter, current-mode control, fast-scale bifurcation, slow-scale bifurcation, chaos.

\section{INTRODUCTION}

Current mode controlled dc-dc converters are inherently nonlinear, non-smooth time varying systems. Their nonlinear behavior has been extensively studied in various publications (Banerjee et al., 2001; di Bernardo et al., 1998; Fossas and Olivar, 1996). The literature shows that two different types of nonlinearities can occur, slow scale (El Aroudi et al., 1999) and fast scale (Banerjee and Chakrabarty, 1998; Chakrabarty et al., 1996) bifurcations. These bifurcations had been separately investigated as the outer voltage loop which had generally been believed to cause the slow-scale bifurcation is much slower than the inner current loop which causes the fast-scale bifurcation and the two loops were believed not to interact with each other. However, it has recently been demonstrated (Chen et al., 2007) that the two mechanisms responsible for the fast-scale and slow-scale bifurcations can actually interact.

Higher order dc-dc converters, such as the Ćuk converter, have a significant advantage over other inverting topologies since they enable low voltage ripple on both the input and the output sides of the converter. For such higher order dc-dc converters operating under cascade control, both fast-scale bifurcation and slow-scale bifurcation have been reported (Tse, 2003). These studies had suggested that the fast-scale bifurcation occurs in the presence of an inner current loop, while the slow-scale bifurcation occurs in the presence of the outer voltage control loop.

In this paper, we observe that a slow-scale bifurcation can still occur in a Ćuk converter operating without an outer voltage loop after the system goes into chaos as a result of increasing the reference current. We will study and stabilize this phenomenon, ignored in previous studies, using an approach based on the system's state transition matrix over a full cycle (Leine et al., 2000). This method has previously been used by the authors to control the fast-scale bifurcation in simple low-order dc-dc converters (Giaouris et al., 2007; Giaouris et al., 2006) with fruitful results. In this paper, the analysis is extended to show that a Ćuk converter may exhibit a fast-slow scale interacting bifurcation even in the absence of the output voltage feedback signal. Based on the analysis, novel controllers to avoid the interacting bifurcation are proposed and validated. Using this controller it is possible to achieve a bigger operating region where the converter can operate. The practical significance of that approach is that we can use this methodology to design new smaller and hence cheaper converters with big operating regions. This line of work along with its experimental validation will be presented at a future publication.

\section{2. ĆUK CONVERTER OPERATING UNDER OPEN LOOP CURRENT-MODE CONTROL}

\subsection{Principles of operation}

The fourth order, open loop current-mode controlled Ćuk converter is shown in Fig. 1. Unlike other simple low order converters, the Ćuk converter can operate in continuous conduction mode and in a number of discontinuous modes. For simplicity, we will focus on operation in the continuous conduction mode. The reference current $I_{\text {ref }}$ compared with the sum of the inductor currents $i_{1}+i_{2}$ generates the ON-OFF driving signal for the switch $\mathrm{S}_{\mathrm{T}}$. As the sum of the inductor currents $i_{1}+i_{2}$ reaches the value of the reference current $I_{r e f}$, $\mathrm{S}_{\mathrm{T}}$ is turned OFF, and remains OFF until the start of the next clock cycle. 
Converter operation is governed by two sets of linear differential equations related to the $\mathrm{ON}$ and $\mathrm{OFF}$ states. The ON state equations of the system can be written as:

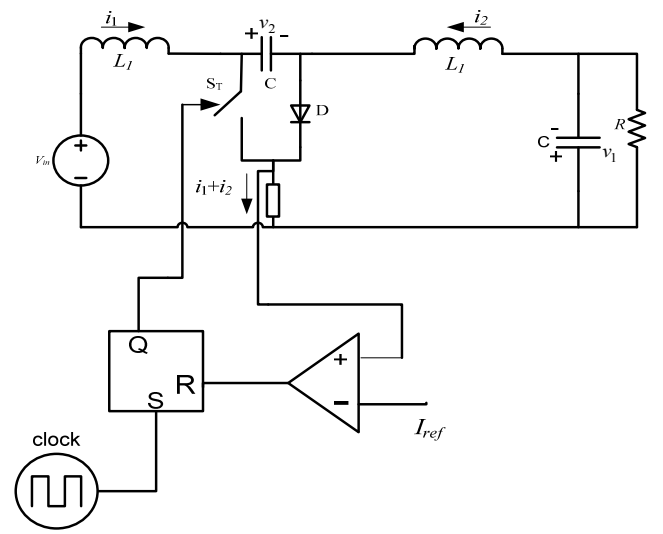

Fig. 1. Cuk converter with open loop current-mode control

$$
\left.\begin{array}{l}
\dot{x}_{1}=\frac{x_{3}}{C_{2}}-\frac{x_{1}}{C_{2} R}, \quad \dot{x}_{2}=-\frac{x_{3}}{C_{1}} \\
\dot{x}_{3}=\frac{x_{2}}{L_{2}}-\frac{x_{1}}{L_{2}}, \quad \dot{x}_{4}=\frac{V_{i n}}{L_{1}}
\end{array}\right\}
$$

and when the switch is turned OFF:

$$
\left.\begin{array}{l}
\dot{x}_{1}=\frac{x_{3}}{C_{2}}-\frac{x_{1}}{C_{2} R}, \dot{x}_{2}=\frac{x_{4}}{C_{1}} \\
\dot{x}_{3}=-\frac{x_{1}}{L_{2}}, \quad \dot{x}_{4}=-\frac{x_{2}}{L_{1}}+\frac{V_{i n}}{L_{1}}
\end{array}\right\}
$$

The state variables of the system are the output voltages and inductor currents $\left(v_{1}=x_{1}, v_{2}=x_{2}, i_{1}=x_{3}, i_{2}=x_{4}\right)$.

In matrix form this may be written as:

$$
\begin{array}{ll}
\dot{\mathbf{X}}=\mathbf{A}_{1} \mathbf{X}+\mathbf{B}_{1} \mathbf{U} & \mathrm{S}_{\mathrm{T}} \text { is ON and D is OFF } \\
\dot{\mathbf{X}}=\mathbf{A}_{2} \mathbf{X}+\mathbf{B}_{2} \mathbf{U} & \mathrm{S}_{\mathrm{T}} \text { is OFF and D is ON }
\end{array}
$$

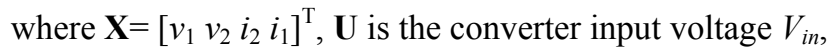

$\mathbf{A}_{1}=\left[\begin{array}{cccc}-1 / C_{2} R & 0 & 1 / C_{2} & 0 \\ 0 & 0 & -1 / C_{1} & 0 \\ -1 / L_{2} & 1 / L_{2} & 0 & 0 \\ 0 & 0 & 0 & 0\end{array}\right]$,

$\mathbf{A}_{2}=\left[\begin{array}{cccc}-1 / C_{2} R & 0 & 1 / C_{2} & 0 \\ 0 & 0 & 0 & 1 / C_{1} \\ -1 / L_{2} & 0 & 0 & 0 \\ 0 & -1 / L_{1} & 0 & 0\end{array}\right]$ and $\mathbf{B}=\left[\begin{array}{c}0 \\ 0 \\ 0 \\ \frac{1}{L_{1}}\end{array}\right]$

The control equation can be expressed as:

$i_{1}+i_{2}-I_{\text {ref }}=0$

\subsection{Bifurcation behaviour}

With the circuit parameters fixed at $V_{i n}=15 V, T=200 \mu \mathrm{s}$, $L_{1}=L_{2}=L=16 \mathrm{mH}, C=4.7 \mu \mathrm{F}$ and $R=75 \Omega$, numerical simulation can be performed using the above equations. A typical bifurcation diagram is shown in Fig. 2, using $I_{\text {ref }}$ as the bifurcation parameter. For values of $I_{\text {ref }}$ below $0.5 \mathrm{~A}$, the system is attracted to the period-1 orbit, as can be seen in Fig. 3. At $I_{r e f}=0.5 \mathrm{~A}$ the system loses stability and gives way to a period-2 orbit (fast-scale bifurcation), as shown in Fig. 4. If the value of $I_{\text {ref }}$ is further increased, the system is stroked by a border collision at $I_{r e f}=0.59 \mathrm{~A}$ before it goes into chaos (Fig. 5). A detailed study of this behaviour was given in (Tse, 2003) up to a value of $I_{r e f}=0.74 \mathrm{~A}$, ignoring values of $I_{r e f}$ beyond this point where the interacting bifurcation is observed at $I_{r e f}=0.75 \mathrm{~A}$, as shown in Fig. 6 .

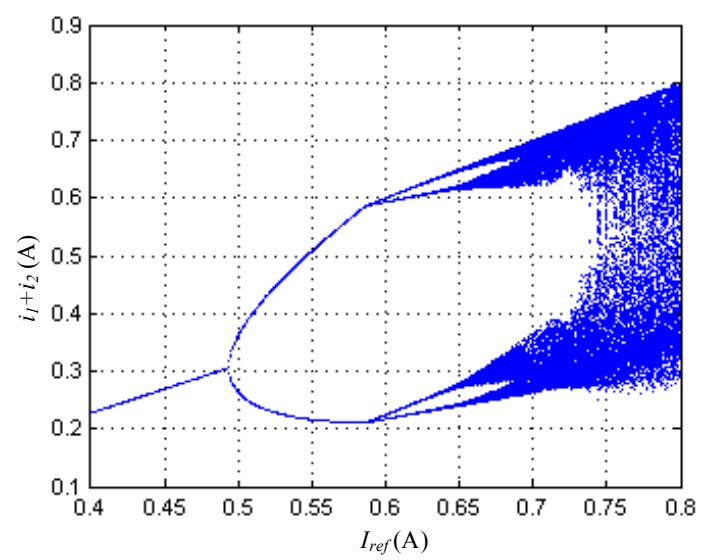

Fig. 2. Bifurcation diagram of the Ćuk converter with open loop currentmode control

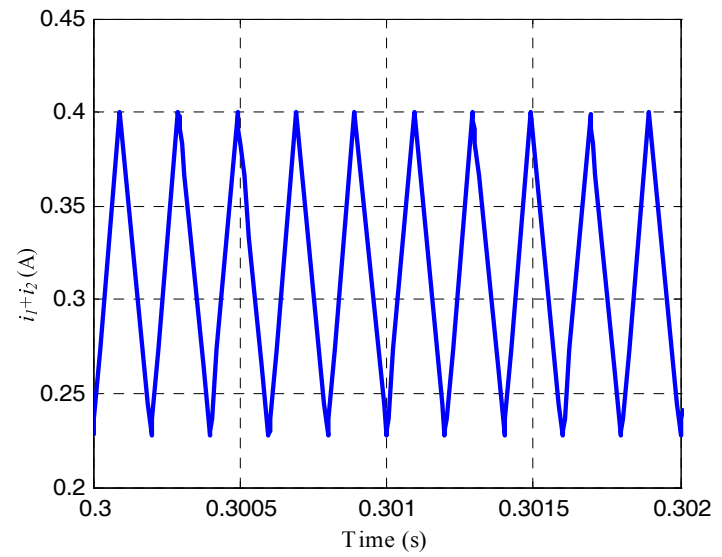

Fig. 3. Sum of the inductor currents; period-1 orbit with $I_{r e f}=0.4 \mathrm{~A}$.

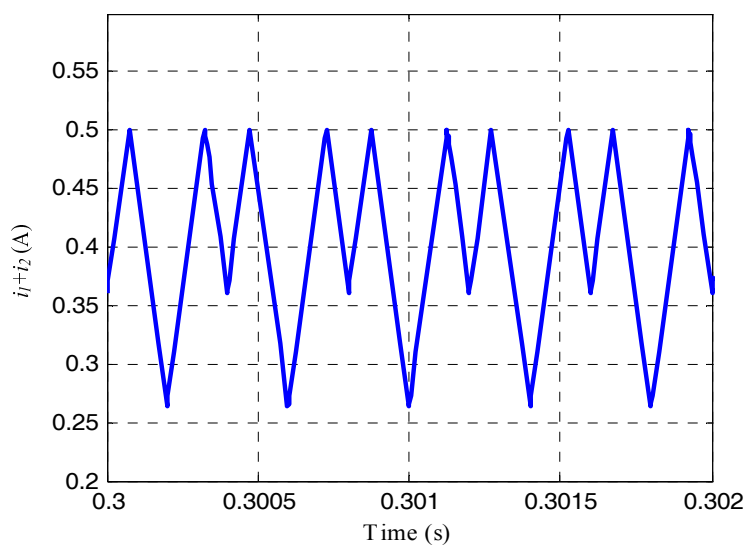

Fig. 4. Sum of the inductor currents; period- 2 orbit with $I_{r e f}=0.5$ A. 


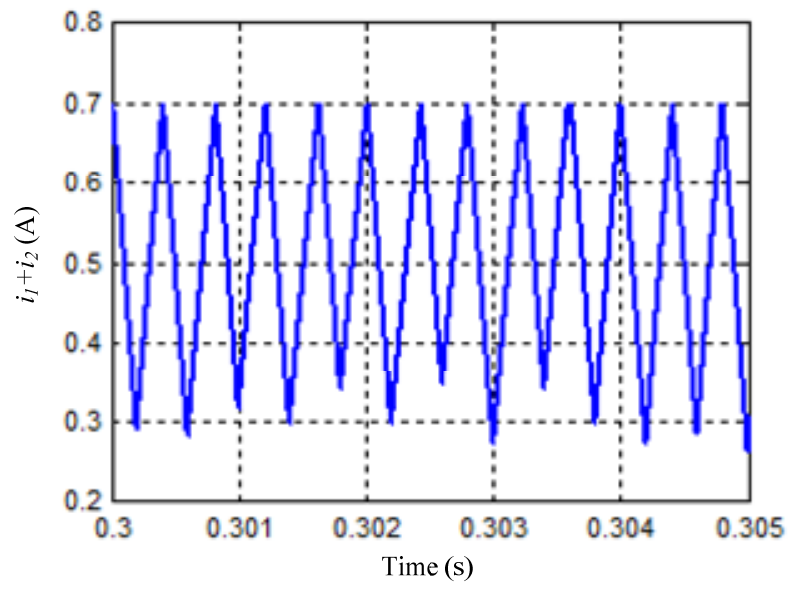

Fig. 5. Sum of the inductor currents; chaos with $I_{r e f}=0.7$ A.

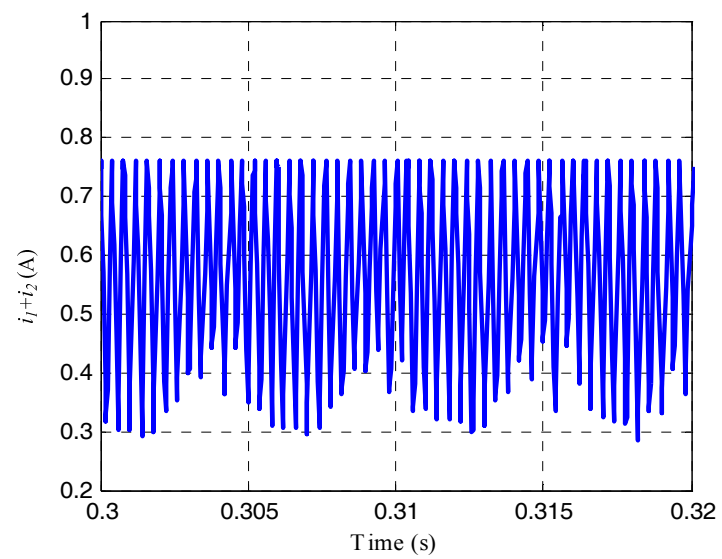

Fig. 6. Sum of the inductor currents; fast-slow scale bifurcation with $I_{\text {ref }}=0.75 \mathrm{~A}$.

\section{STABILITY ANALYSIS OF THE OPEN LOOP CURRENT-MODE CONTROLLED CUK CONVERTER}

\subsection{Derivation of the monodromy matrix}

The stability of the converter circuit can be analyzed by deriving the eigenvalues of the monodromy matrix (Floquet or characteristic multipliers) of the system. To study the stability of the period-1 orbit, it is sufficient to consider $t$ varying from 0 to $T$. Fig. 7 , shows that the period 1 orbit in the state space crosses the switching hypersurface at $d T$ (when the switch is turned OFF); $d$ is the duty cycle and $T$ is the switching period. The monodromy matrix $\mathbf{W}$ of the system for one cycle can be expressed as:

$$
\mathbf{W}(T, 0)=e^{\mathbf{A}_{2} T(1-d)} \times \mathbf{S} \times e^{\mathbf{A}_{1} d T}
$$

where $S$ is the saltation matrix at $\mathrm{d} T$, and can be obtained by using the following formula (Giaouris et al., 2008):

$$
\mathbf{S}=\mathbf{I}+\frac{\left(\mathbf{f}_{+}(x(t))-\mathbf{f}_{-}(x(t))\right) \mathbf{n}^{T}}{\mathbf{n}^{T} \mathbf{f}_{-}+\left.\frac{\partial h}{\partial t}\right|_{t=d T}}
$$

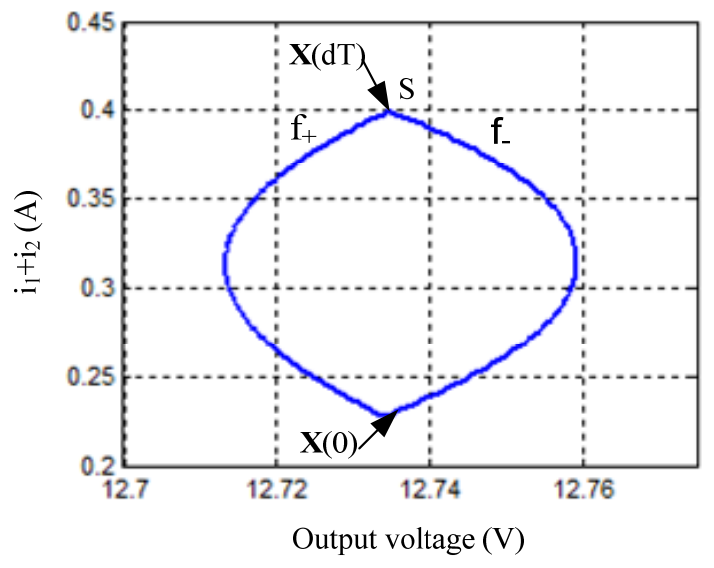

Fig. 7. Period 1 orbit

where $h$ is the switching condition, $\mathbf{n}$ is the normal vector to $h, t$ is the switching time, and $\mathbf{f}_{+}$and $\mathbf{f}_{-}$are the two vector fields before and after the switching hypersurface. Since the switching equation (3) is not a function of time, the derivative of $h$ with respect to time is zero $(\partial h / \partial t=0)$.

The switching hypersurface $h$ at the OFF switching is given by:

$h(X,(d T))=x_{3}(d T)+x_{4}(d T)-I_{r e f}$

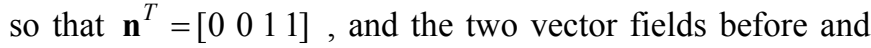
after the switching are:

$\mathbf{f}_{+}(x(t))=\left[\begin{array}{c}-x_{1}(t) / R C+x_{2}(t) / C \\ x_{4}(t) / C \\ -x_{1}(t) / L \\ -x_{2}(t) / L+V_{i n} / L\end{array}\right]_{t=d T}$
$\mathbf{f}_{-}(x(t))=\left[\begin{array}{c}-x_{1}(t) / R C+x_{2}(t) / C \\ x_{3}(t) / C \\ -x_{1}(t) / L+x_{2}(t) / C \\ V_{\text {in }} / L\end{array}\right]_{t=d T}$

The stability of the system can be determined by calculating the eigenvalues of the monodromy matrix $\mathbf{W}$ :

$\operatorname{det}[\lambda \mathbf{1}-\mathbf{W}]=0$

To evaluate $\mathbf{W}$, and hence the stability of the system, the values of the state vectors $\mathbf{X}(0)$ and $\mathbf{X}(d T)$ need to be numerically calculated (Daho et al., 2008) .

\subsection{Evaluation of the eigenvalues}

In this section, we will focus on the evolution of the eigenvalues as $I_{r e f}$ is varied. If all the Floquet multipliers are inside the unit circle, the system is stable. Any crossing of the eigenvalues from the interior to the exterior of the unite circle indicates a loss of stability, i.e. a bifurcation occurs at that crossing point. A fast-scale bifurcation occurs when a negative real eigenvalue moves out the unit circle and a slowscale bifurcation occurs when a complex eigenvalue moves 
out the unit circle. An interacting bifurcation occurs if both conditions are satisfied. Results (obtained using the same parameters given in section 2.2) are shown in Table 1. A fastscale bifurcation occurs at $I_{r e f}=0.5 \mathrm{~A}$ and an interacting bifurcation at $I_{r e f}=0.75 \mathrm{~A}$. This is in good agreement with the simulation results produced in the previous section

\section{Table 1. Floquet multiplier of the Ćuk converter}

\begin{tabular}{|c|c|l|l|l|}
\hline \multirow{2}{*}{$\mathrm{I}_{\text {ref }}$} & \multicolumn{3}{|c|}{ Eigenvalues } & \multirow{2}{*}{ Remarks } \\
\cline { 2 - 4 } & \multicolumn{2}{|c|}{ Real Eigenvalues } & $\begin{array}{l}\text { Modulus } \\
\text { Complex } \\
\text { Pair) }\end{array}$ & \\
\hline 0.4 & -0.8510 & 0.9548 & 0.9931 & Stable \\
\hline 0.49 & -0.9944 & 0.9545 & 0.9945 & Stable \\
\hline $\mathbf{0 . 5}$ & $\mathbf{- 1 . 0 0 9 2}$ & $\mathbf{0 . 9 5 4 5}$ & $\mathbf{0 . 9 9 5 2}$ & Period-2 \\
\hline 0.55 & -1.0836 & 0.9543 & 0.9962 & Period-2 \\
\hline 0.6 & -1.1547 & 0.9542 & 0.9971 & $\begin{array}{l}\text { Chaotic } \\
\text { motion }\end{array}$ \\
\hline 0.65 & -1.2231 & 0.9540 & 0.9981 & $\begin{array}{l}\text { Chaotic } \\
\text { motion }\end{array}$ \\
\hline 0.7 & -1.2890 & 0.9538 & 0.9991 & $\begin{array}{l}\text { Chaotic } \\
\text { motion }\end{array}$ \\
\hline $\mathbf{0 . 7 5}$ & $\mathbf{- 1 . 3 5 2 6}$ & $\mathbf{0 . 9 5 3 7}$ & $\mathbf{1}$ & $\begin{array}{l}\text { Interacting } \\
\text { bifurcation }\end{array}$ \\
\hline 0.8 & -1.4142 & 0.9535 & 1.0009 & $\begin{array}{l}\text { Interacting } \\
\text { bifurcation }\end{array}$ \\
\hline
\end{tabular}

\subsection{Bifurcation lines in $I_{r e f}$ and $R$ parameter space}

In this section, we obtain the bifurcation lines for the fastscale bifurcation and the slow- scale bifurcation in the $I_{\text {ref }}$ and $R$ parameter plane. The load resistance $R$ is varied in the

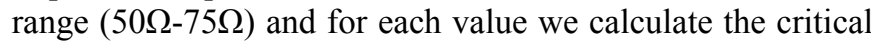
value of $I_{\text {ref }}$ for which either, a slow-scale or a fast-scale bifurcation occurs (other parameters being fixed). The two bifurcation lines are shown in Fig. 8, where the two lines define regions of stable operation, fast-scale unstable operation, and interacting bifurcation operation. Such bifurcation lines provide essential information for the designer allowing the selection of system parameters in an informed manner. At this point it has to be noted that Fig. 8 indicates that there is no point where the two bifurcation lines intersect, i.e. we always have first a fast scale and then a slow scale bifurcation. Other systems have shown to exhibit a true interaction where the two lines intersect, i.e. at the same value of the bifurcation parameter we have one real eigenvalue at -1 and two complex on the unit circle.

\section{CONTROL OF THE FAST-SLOW SCALE BIFURCATION VIA THE MONODROMY MATRIX}

From equation (4), it is clear that the saltation matrix $\mathbf{S}$ plays an important role in determining the eigenvalues of the monodromy matrix, and hence the stability of the system. This leads to the possibility of altering the stability properties of the system by changing the parameters of $\mathbf{S}$.

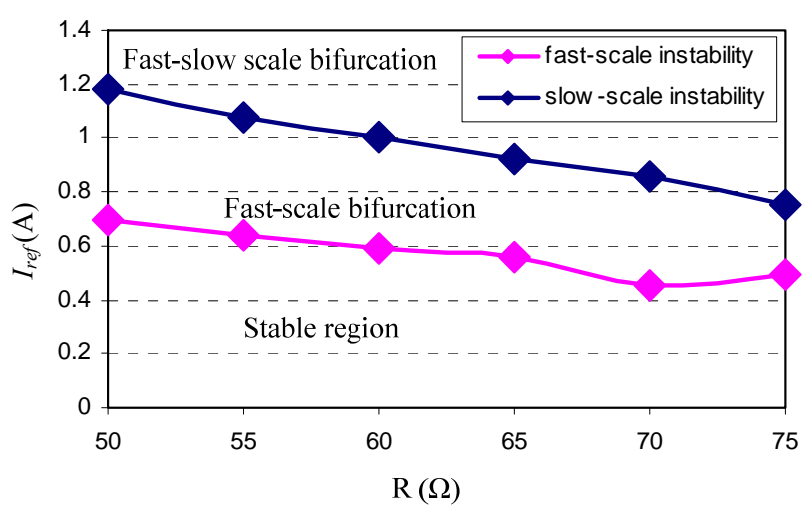

Fig. 8. Bifurcation lines in the $R-I_{\text {ref }}$ parameter plane

Equation (5) shows that the saltation matrix $\mathbf{S}$ depends on the

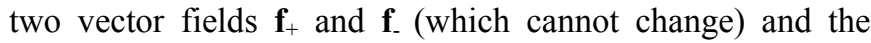
switching manifold $h$. We can either alter $h$ to change the normal vector $\mathbf{n}$ (changing the slope of the switching manifold), or we can simply add a time varying component that will change the term $\partial h / \partial t$ to a non-zero value. By monitoring the bifurcation variable we can make these small changes and we can therefore force the eigenvalues to remain inside the unit circle by changing the saltation matrix $\mathbf{S}$. Based on this simple idea, two methods are proposed in this section to control the fast-scale and the interacting bifurcation in the open loop current-mode controlled Ćuk converter and guarantee stability over a substantially wider range of the bifurcation variable.

\subsection{Changing the length of the normal vector}

This control method is based on the idea of changing the normal vector $\mathbf{n}$ by adding a component to the current feedback signal. This will change the third and the forth coordinate of the normal vector $\mathbf{n}$ since we are using $i_{1}+i_{2}$ as a current feedback signal. In this case, the switching hypersurface $h$ can be expressed as:

$h(\mathbf{X},(d T))=(1+a) \times\left(x_{3}(d T)+x_{4}(d T)\right)$

And the normal vector $\mathbf{n}$ to the switching hypersurface $h$ is $\mathbf{n}=\nabla h(\mathbf{X}, T)=\left[\begin{array}{llll}0 & 0 & 1+a & 1+a\end{array}\right]^{T}$

It is obvious that the eigenvalues of the monodromy matrix will be a function of the parameter $a$. A controller may now be designed to place the eigenvalues inside the unit circle (in this case at a circle of radius -0.9750). This can be achieved by solving the nonlinear equation.

$\mid \operatorname{eig}(\mathbf{W}(\mathrm{T}, 0, \mathbf{X}(0) \mid-0.9750=0$

The numerical solution of this equation is plotted in Fig. 9. A look-up table can now be used to propose a supervising controller that adjusts the value of $a$ depending on the value of $I_{r e f}$. Figures 10 and 11 show the action of this controller to stabilize the system at $I_{r e f}=0.5 \mathrm{~A}$, where the system would normally be affected by the fast-scale bifurcation, and at $I_{r e f}=0.75 \mathrm{~A}$, where the system would normally be affected by the fast-slow scale bifurcation. It is clear that instability is avoided in both cases and the system settles down to the stable period-1 limit cycle after a small transient. 


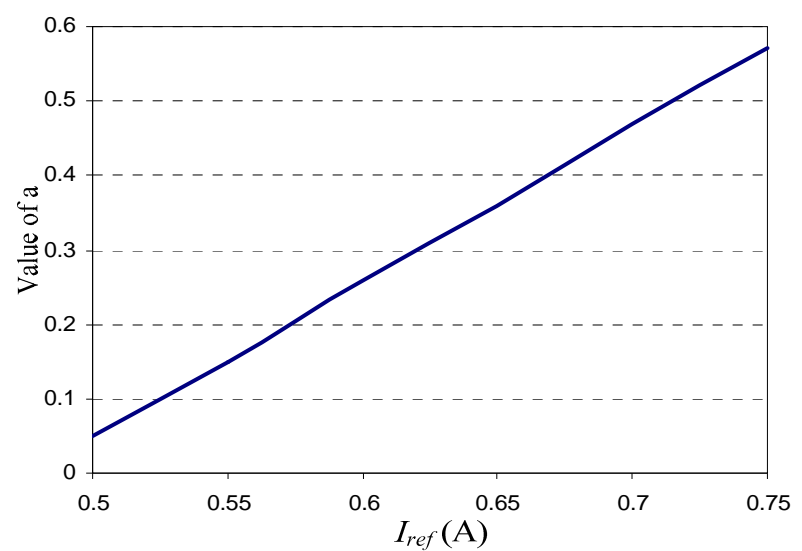

Fig. 9. Values of $a$ to maintain stability.

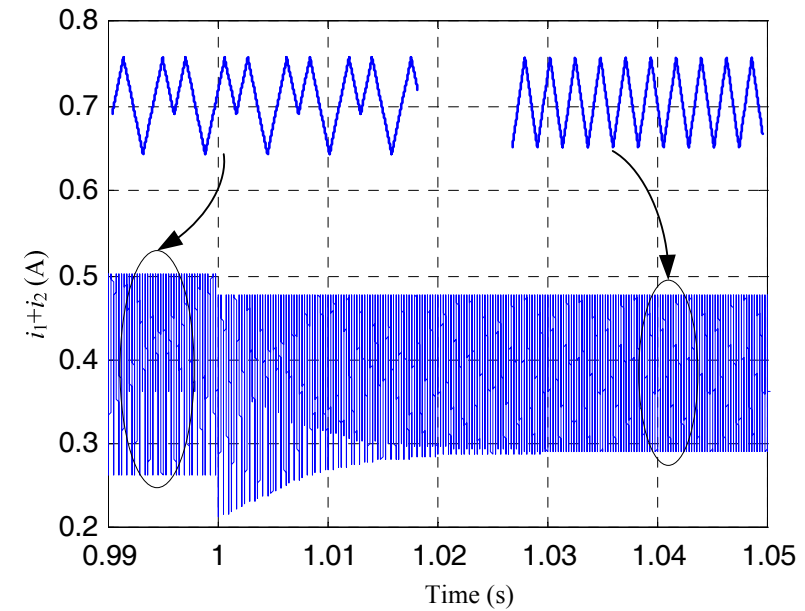

Fig. 10. Time response showing the action of the first controller to stabilize the system at $I_{r e f}=0.5 \mathrm{~A}$ where the system is normally unstable as a result of a fast-scale bifurcation.

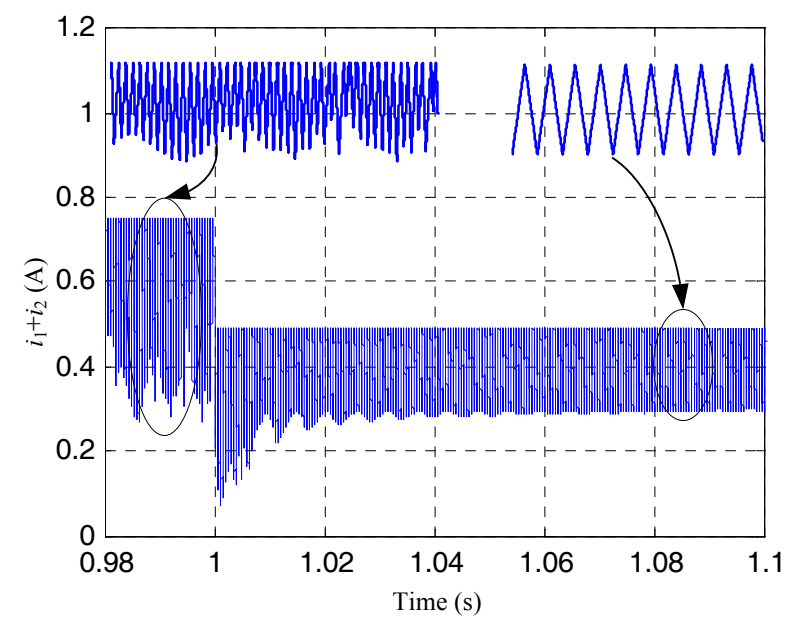

Fig. 11. Time response showing the action of the first controller to stabilize the system at $I_{r e f}=0.75 \mathrm{~A}$ where the system is normally unstable as a result of a fast-slow scale bifurcation.

\subsection{Adding a sinusoidal signal to $I_{\text {ref }}$}

In this method, a small sinusoidal signal is added to the reference current such that $I_{\text {ref }}=I_{\text {ref }}\left(1+A \sin \left(\omega_{s} t\right)\right.$., where $\omega_{\mathrm{s}}$ is the perturbation frequency set to the converter switching frequency $\left(\omega_{s}=2 \pi / T\right)$. This will affect the time derivative of $h$.

$$
\begin{aligned}
& h(\mathbf{X},(d T))=\left(x_{3}(d T)+x_{4}(d T)\right)-I_{r e f}\left(1+A \sin \left(\omega_{s} t\right)\right) \\
& d h(\mathbf{X},(d T)) / d t=I_{r e f} \times A \times \omega_{s} \times \cos (2 \pi d) \\
& \mathbf{S}(d T)=\mathbf{I}+\frac{\left(\mathbf{f}_{+}-\mathbf{f}_{-}\right) \mathbf{n}^{T}}{\mathbf{n}^{T} \mathbf{f}_{-}+I_{r e f} \times A \times \omega_{s} \times \cos (2 \pi d)}
\end{aligned}
$$

The value of $A$ to maintain stability can again be calculated by solving the following nonlinear transcendental equation.

$\operatorname{eig}(\mathbf{W}(\mathrm{T}, 0, \mathbf{X}(0) \mid-0.9250=0$

The numerical solution of this equation is plotted in Fig. 12. Figs. 13 and 14 show the action of this controller to stabilize the system at $I_{r e f}=0.5 \mathrm{~A}$, where the system would normally be affected by the fast-scale bifurcation, and at $I_{r e f}=0.75 \mathrm{~A}$, where the system would normally be affected by the fastslow scale bifurcation. In both cases, the instability is avoided.

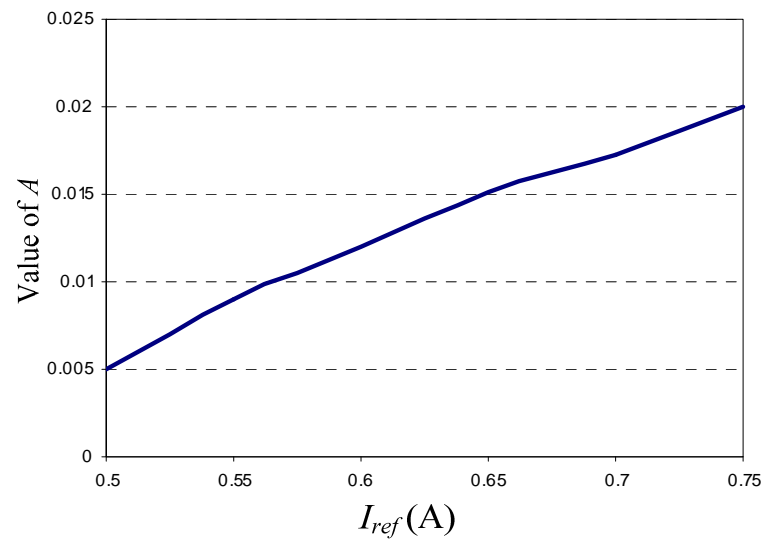

Fig. 12. Values of $A$ to maintain stability.

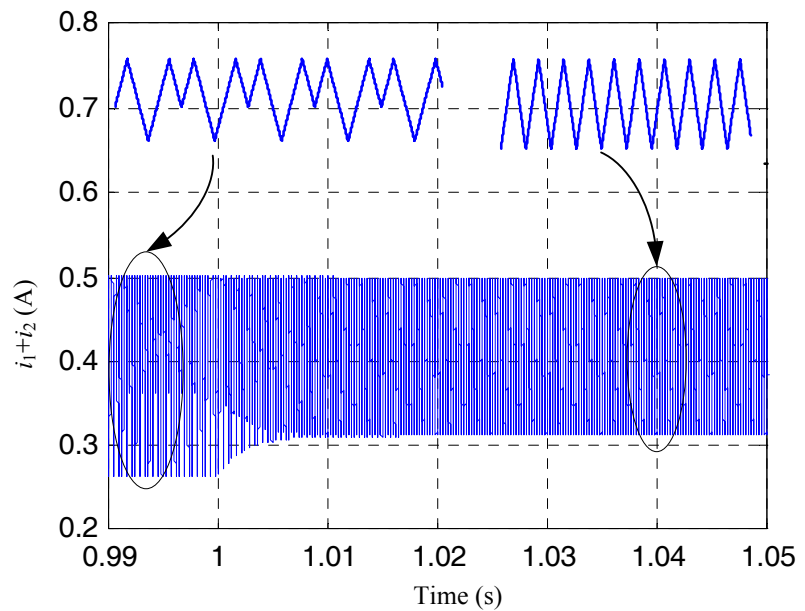

Fig. 13. Time response showing the action of the second controller to stabilize the system at $I_{r e f}=0.5 \mathrm{~A}$ where the system is normally unstable as a result of a fast-scale bifurcation. 


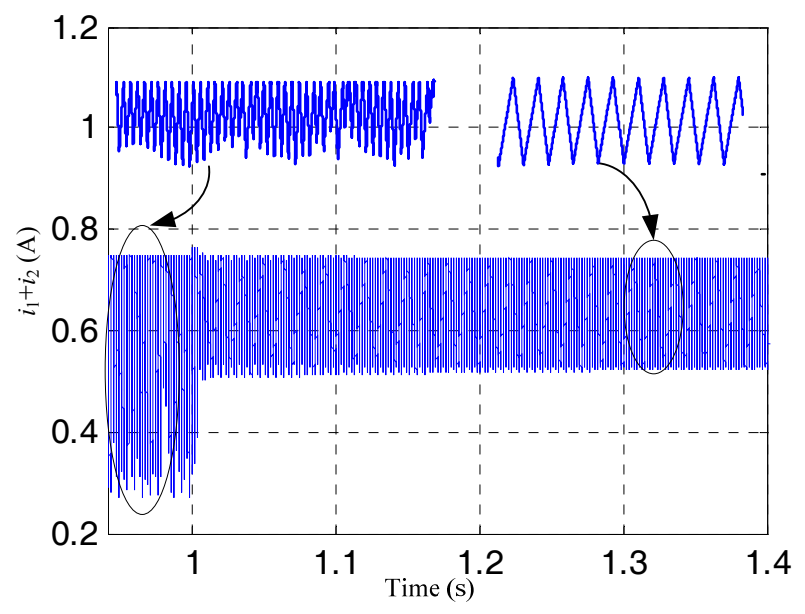

Fig. 14. Time response showing the action of the second controller to stabilize the system at $I_{r e f}=0.75 \mathrm{~A}$ where the system is normally unstable as a result of a fast-slow scale bifurcation.

\section{CONCLUTION}

An open loop current-mode controlled Ćuk converter has been studied to demonstrate that higher order dc-dc converters operating with an inner current control loop can induce fast-slow scale bifurcation in the absence of an outer voltage closed loop. The phenomenon has been analyzed using the complete-cycle solution matrix (the monodromy matrix) of the system. Based on the expression for the saltation matrix of the system, we have proposed two possible controllers to control the fast and fast-slow scale bifurcations that normally occur in this circuit. Both controllers provide good results without adding any complicated control law.

\section{REFERENCES}

Banerjee, S., and Chakrabarty, K. (1998). Nonlinear modeling and bifurcations in the boost converter. IEEE Transactions on Power Electronics, vol.13, pp.252-260.

Banerjee, S., Verghese, G. (2001). Nonlinear Phenomena in Power Electronics: Bifurcations, Chaos, Control, and Application (New York: IEEE Press).

Chakrabarty, K., Poddar, G., and Banerjee, S. (1996). Bifurcation behavior of the buck converter. IEEE Transactions on Power Electronics, vol.11, pp.439-447.

Chen, Y., Tse, C.K., Wong, S., and Qiu, S. (2007). Interaction of Fast-Scale and Slow-Scale Bifurcations in Current-Mode Controlled dc-dc Converters.

International Journal of Bifurcation and Chaos, Vol. 17, pp.1609-1622

Daho, I., Giaouris, D., Zahawi, B., Picker, V., and Banerjee, S. (2008). Stability analysis and bifurcation control of hysteresis current controlled Cuk converter using Filippov's method. PEMD. 4th IET Conference on Machines and Drives, pp.381-385.

di Bernardo, M., Garefalo, F., Glielmo, L., and Vasca, F. (1998). Switchings, bifurcations, and chaos in DC/DC converters. IEEE Transactions on Circuits and Systems$I$, vol.45, pp.133-141.
El Aroudi, A., Benadero, L., Toribio, E., and Olivar, G. (1999). Hopf bifurcation and chaos from torus breakdown in a PWM voltage-controlled DC-DC boost converter. IEEE Transactions on Circuits and SystemsI, vol.46, pp.1374-1382.

Fossas, E., and Olivar, G. (1996). Study of chaos in the buck converter. IEEE Transactions on Circuits and Systems$I$, vol.43, pp.13-25.

Giaouris, D., Banerjee, S., Zahawi, B., and Pickert, V. (2007). Control of Fast Scale Bifurcations in PowerFactor Correction Converters. IEEE Transactions on Circuits and Systems-II, vol.54, pp.805-809.

Giaouris, D., Banerjee, S., Zahawi, B., and Pickert, V. (2008). Stability Analysis of the Continuous Conduction Mode Buck Converter via Filippov's Method. IEEE Transactions on Circuits and Systems-II, vol.55, pp.1084-1096.

Giaouris, D., Elbkosh, A., B.Soumitro, B.Zahawi, and Volker, P. (2006). Control of switching circuits using complex-cycle solution matrices. IEEE International Conference on Industrial Technology.

Leine, R.I., Campent, D.H.V., and de Vrande, B.L.V. (2000). Bifurcations in Nonlinear Discontinuous Systems. Springer, vol.23, pp.105-164.

Tse, C.K. (2003). Complex Behavior of Switching Power Converters (CRC Press). 